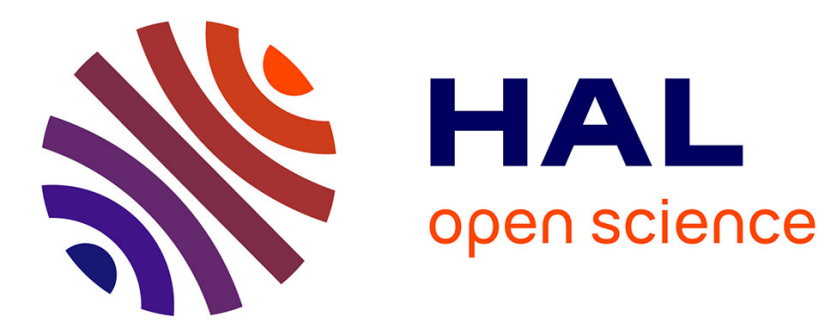

\title{
McDowell's Conceptualist Therapy for Skepticism
}

Santiago Echeverri

\section{To cite this version:}

Santiago Echeverri. McDowell's Conceptualist Therapy for Skepticism. European Journal of Philosophy, 2011, 19 (1), pp.1-30. 10.1111/j.1468-0378.2009.00383.x . ijn_00452517

\section{HAL Id: ijn_00452517 \\ https://hal.science/ijn_00452517}

Submitted on 2 Feb 2010

HAL is a multi-disciplinary open access archive for the deposit and dissemination of scientific research documents, whether they are published or not. The documents may come from teaching and research institutions in France or abroad, or from public or private research centers.
L'archive ouverte pluridisciplinaire HAL, est destinée au dépôt et à la diffusion de documents scientifiques de niveau recherche, publiés ou non, émanant des établissements d'enseignement et de recherche français ou étrangers, des laboratoires publics ou privés. 


\title{
McDowell's Conceptualist Therapy for Skepticism
}

\author{
Santiago Echeverri
}

\begin{abstract}
In Mind and World, McDowell conceives of the content of perceptual experiences as conceptual. This picture is supposed to provide a therapy for skepticism, by showing that empirical thinking is objectively and normatively constrained. The paper offers a reconstruction of McDowell's view and shows that the therapy fails. This claim is based on three arguments: 1) the identity conception of truth he exploits is unable to sustain the idea that perception-judgment transitions are normally truth conducing; 2) it could be plausible only from an externalist point of view that is in tension with the view of normativity that motivates conceptualism; 3) the identity conception of truth is incompatible with McDowell's recent version of conceptualism in terms of 'non-propositional intuitive contents'.
\end{abstract}

In the last few years, a picture of perceptual experience as a source of reasons has emerged in the philosophical scene. This view interprets the epistemic status of perception in terms of its role in the justification of doxastic states. Some of its defenders claim that, if an account on these lines were not attained, the epistemic character of perceptual experience would be threatened, leading to a form of skepticism about the external world.

In this paper I shall focus on the conceptualist defense of this claim and, in particular, on McDowell's accounts of it: the picture he provides in Mind and World, where concepts are conceived as constituents of facts, and his most recent proposal, where concepts are conceived as actualized in non-propositional intuitive contents (McDowell 2007, 2008a).

I am going to argue for the following claim: the conceptualist picture of perceptual content as identical to facts does not provide a way out for skepticism about the possibility of knowledge. Since this sort of skepticism is one of the motivations for Davidson's coherentism —one of the targets of McDowell's main argument- conceptualism fails on this count. If I am right, this paves the way for a picture that takes beliefs as the minimal units of justification. Furthermore, if one shows that the hypothesis that perceptual content is conceptually structured doesn't improve the coherentist view, one can argue that the content of perception is non-conceptual. Before we reach these conclusions, it is necessary to make some methodological remarks.

European Journal of Philosophy w1:n ISSN 0966-8373 pp. 1-30 (C) 2009 Blackwell Publishing Ltd., 9600 Garsington Road, Oxford OX4 2DQ, UK and 350 Main Street, Malden, MA 02148, USA. 


\section{Three Attitudes Against Skepticism}

In the recent literature, different sorts of anti-skeptical projects have been delineated. Following Pryor (2000: 517), one can distinguish ambitious antiskeptical projects from modest anti-skeptical projects. The former try to 'refute the skeptic on his own terms, that is, to establish that we can justifiably believe and know such things as that there is a hand, using only premises that the skeptic allows us to use'. If one intended to develop this project in the context of a theory of perception, one should restrict evidence to bits of experience that don't give rise to doubt. In contrast, the modest anti-skeptical project purports 'to establish to our own satisfaction that we can justifiably believe and know such things as that there is a hand, without contradicting obvious facts about perception'.

Modest projects come in different varieties. This is due to the fact that one can engage with the skeptic, not by refuting him on his own terms but by bringing into question the main assumptions of the skeptical challenge, or by providing an alternative picture that looks more appealing than the skeptical stance. In this sense, one can distinguish dogmatist projects from therapeutic projects. Dogmatists claim permission to speak about perceptual knowledge (or justification), even though they have no means to show that the skeptic is wrong; by contrast, therapists go farther and promote a conversion of the skeptic. ${ }^{1}$ Whereas dogmatists refuse to take skepticism seriously, therapists take it seriously, although they think it worse to look for anti-skeptical arguments. ${ }^{2}$

Although therapists do not provide a refutation of the skeptic, their discourse has a far-reaching normative character: it purports to give us reasons not to be worried about skeptical problems. A source of inspiration for this project can be found in Wittgenstein's remarks in the Philosophical Investigations:

[T]he clarity that we are aiming at is indeed complete clarity. But this simply means that the philosophical problems should completely disappear.

The authentic discovery is the one that makes me capable of stopping doing philosophy when I want to.- The one that gives philosophy peace, so that it is no longer tormented by questions that bring itself in question. (Wittgenstein 1953, § 133: 51)

There is no recipe to prescribe therapies. However, all the therapists put forward an alternative picture intended to supersede the skeptical outlook, i.e. a picture that makes us capable of stopping doing philosophy. In this case, the picture should enable us to stop trying to prove the skeptic is wrong. Hence, one can see conceptualism as providing an alternative picture to skepticism and evaluate it by measuring its potential to dissolve the skeptical challenge. ${ }^{3}$

I am sympathetic to the claim that sometimes a therapy is a better alternative than a solution. My objections are not against the therapeutic strategy but against the sort of therapy McDowell prescribes. To make an analogy with the medical case: conceptualism is based on a mistaken diagnosis of the skeptical problem 
that motivates coherence theories; this has led it to prescribe the wrong treatment. In other words, providing an adequate picture of perceptual content is orthogonal to the task of dissolving skepticism. ${ }^{4}$

The remaining paper is in seven sections. Section 2 provides a reconstruction of McDowell's early version of conceptualism and shows how it is supposed to dissolve skepticism. Sections 3 and 4 present objections against this therapeutic project: I show that the identity conception of truth cannot forestall the emergence of skepticism, and it is committed to a dubious ontology. Sections 5 and 6 present some ways of patching conceptualism, and show that they conflict with its main motivations. Section 7 examines an objection against my reading of the skeptical problem, and clarifies its relation to the debate on disjunctivist views of perceptual experience. In section $8 \mathrm{I}$ conclude that, as far as skepticism is concerned, it is possible to take beliefs as the minimal units of justification, and ascribe a non-conceptual content to perception.

\section{The Conceptualist Therapy}

Conceptualists assert that the content of perceptual experience is conceptual. To be sure, the plausibility of this position depends on how one understands the notion of a concept. McDowell has provided two versions of this claim. For the time being, I shall focus on the earlier, more influential version. Later on, in section 6, I shall briefly examine his most recent formulation of this claim.

According to the earlier formulation, one can define concepts as the constituents of the content expressed by a 'that'-clause, whenever it is preceded by a psychological verb, like $S$ believes that $p, S$ thinks that $p, S$ sees that $p$, etc. On this approach, it is possible to be either a strong or a weak conceptualist. A strong conceptualist holds that the content of experiences has the same structure as the content of a 'that'-clause. In some cases, the conceptualist moves to the weaker claim that the content of experiences is wholly expressible by means of a 'that'clause. Alternatively, he may hold that, although intentionality is essentially conceptual, it is possible (even necessary) to introduce a non-conceptual level of description that accounts for some of the ingredients of intentionality. ${ }^{5}$

McDowell describes the conceptual as 'unbounded' and paraphrases it by saying that 'there is nothing outside the conceptual' (McDowell 2008b: 259). This has led most readers to interpret him as a strong conceptualist. On this view, the content of perceptual experiences is conceptual through and through. But this conceptualism differs from other versions in a crucial point: it not only restricts all forms of intentionality to the possession of concepts, but also claims that they articulate the content of experiences. Thus, whereas doxastic theorists of perception (or inferentialists) might be seen as denying that there is something like a perceptual content endowed with semantic or intentional properties (for only propositional states like judgments or beliefs represent the world), McDowell claims that perceptual content is conceptual, i.e. that there is a predoxastic level that already involves the actualization of concepts. As Brandom 
usefully puts it, '[h]e thinks that we need a notion of conscious experience that is prejudgmental, but nonetheless through and through conceptually contentful' (Brandom 1998: 369).

This view needs some qualification, though. To capture some details of McDowell's account, it seems necessary to examine his main argument. Although he presents it quite informally, one can construe it in three steps. In the first step, he presents a diagnosis of the skeptical problem. According to this diagnosis, the source of skepticism about the external world is the same as the source of worries about the possibility of content. In the second and third steps, he provides something similar to an inference to the best explanation: he argues that the best way of avoiding skepticism is to develop a conceptualist framework. I suggest his argument is similar to an inference to the best explanation, for it proceeds by elimination of alternatives. However, it is not an inference to the best explanation, since his goal is not to provide an explanatory theory of experience. He just wants to develop an alternative 'picture' that would help us think of experience in a new way.

\section{First Step: Diagnosis}

In the Afterword to Mind and World, McDowell gives some hints on the nature of his therapeutic project. He hypothesizes that traditional problems associated with the possibility of knowledge and intentionality have a common source and, therefore, that they require a common treatment:

I also assume that philosophical concerns about the possibility of knowledge express at root the same anxiety as philosophical concerns about how content is possible, an anxiety about a felt distance between mind and world. Davidson and Rorty usually focus on concerns of the former sort, whereas I focus on concerns of the latter sort; I take it that the underlying thought is the same, that we ought to exorcize the feeling of distance rather than trying to bridge the felt gap. (McDowell 1994: $146-47)^{6}$

It is difficult to understand how both issues are related and why a common framework could be used for such different purposes. However, when we read this paragraph in the light of some of McDowell's papers on these topics, it seems safe to ascribe to him the following two theses: 1) He seems to believe that a skeptic is not in a position to recognize genuine forms of intentionality. In other words, skeptics are unable to make sense of the mind as having a 'world-view'. 2) He appears to hold that a successful theory of content is sufficient to rule out skepticism about the possibility of knowledge. In other words, offering a conceptualist picture of the mind-world relation would promote the conversion of the skeptic and show him that perceptual knowledge is possible.

I find the first claim attractive, but I cannot understand how it could be connected with the conceptualist account of experience. Let me explain. Some 
versions of skepticism offer a picture of the mind as being intelligible without an external world. Against these pictures, one can profitably sketch an externalist account of content that dispels them. As McDowell (1986: 245) puts it, insisting on 'the interpenetration of inner and outer' in a picture of intentionality can help us conceive of the mind as situated in the world. However, this sort of strategy can be developed without assuming that perceptual content is conceptual. One can go externalist and deny conceptualism.?

Another version of skepticism, forcefully attacked by Davidson, arises from a dualistic picture of scheme and content (for discussion, see McDowell 1999: 11617). This picture takes concepts as schemes wholly different from content. In order to avoid this sort of view, one could reject the dualistic picture and conceive of concepts, as they figure in perceptual judgments, as internally related to their sensory content. However, in so doing, one is not committed to a pre-doxastic version of conceptualism.

To sum up, one could sketch an externalist and non-dualistic account of content but resist McDowell's conceptualist picture of experience. ${ }^{8}$

These arguments lead us to the second claim. This sort of skepticism doesn't put the intentionality of experience in jeopardy, but the warrant of human empirical thinking. But, how could a conceptualist avoid this sort of skepticism? McDowell's argument stresses the role of objectivity instead of that of knowledge. His point seems to be that conceptualism is better suited than other views to make room for human thinking as objectively constrained. Since being objectively constrained is a necessary condition of empirical knowledge, showing that empirical thinking is objectively constrained would contribute to developing a picture where knowledge is possible.

\section{Second Step: Some Alternatives}

A first alternative would be to analyze objectivity as a result of the causal influence of the external world in perceptual experience. This idea is present in empiricist theories that introduce 'sense impressions', or 'sense data', as the basic materials of empirical knowledge. Along with Sellars (1956) and Davidson (1982, 1986), McDowell rejects this approach on the following ground: if one conceives perception in these terms, its relation to perceptual beliefs can be causal, but not normative. In other words, accommodating objectivity just in causal terms would sever the normative relation between mind and world; perceptual experience would be unable to offer reasons to justify perceptual beliefs. Thus, McDowell writes:

[P]erhaps this picture secures that we cannot be blamed for what happens at that outer boundary [of the space of reasons], and hence that we cannot be blamed for the inward influence of what happens there. What happens there is the result of an alien force, the causal impact of the world, operating outside the control of our spontaneity. But it is one 
thing to be exempt from blame, on the ground that the position we find ourselves in can be traced ultimately to brute force; it is quite another thing to have a justification. In effect, the idea of the Given offers exculpations where we wanted justifications. (McDowell 1994: 8) ${ }^{9}$

McDowell's use of evaluative expressions like 'blamed' and 'exculpations' suggests that he has in mind an internalist view of justification. On this view, one should not only show that we are warranted to hold $p$, but also that, in holding $p$, we are 'epistemically responsible' for holding $p$. In some sense, McDowell's view contrasts with the one adopted by theorists who take it that the only normative condition that could be imposed on perceptual states in order to be authoritative is to be qualified as 'reliable', 'accurate', 'true' or 'correct'. ${ }^{10}$ An approach along these lines would commit one to a radical externalism about justification, contrary to McDowell's text. Although he doesn't give further support for this view, we shall accept it for the sake of the argument. ${ }^{11}$

The other alternative is to adopt a version of coherentism of the sort advocated by Davidson. This position results from two main ideas: Davidson thinks that coherentism follows from our incapacity to make sense of impressions as reasons for knowledge. On the one hand, if we conceived of impressions on the model of assertions, giving us a 'message' from the external world, they could not ground perceptual knowledge in a satisfactory way. Intuitively, someone who gives a message might be lying. 'Since we can't swear intermediaries to truthfulness, we should allow no intermediaries between our beliefs and their objects in the world' (Davidson 1986: 144). On the other hand, if one understands perceptual content as a causal impact of the external world, one won't have real reasons, because 'nothing can count as a reason for holding a belief except another belief' (141). Thus, Davidson claims that he could eventually develop a theory of knowledge where perceptual states play no normative role in grounding empirical beliefs, although he also thinks that his view could preserve objectivity via the coherence of belief systems. The details of Davidson's view are complex; however, this introduction will do for the present purposes.

McDowell is sympathetic to Davidson's diagnosis but not with his solution. He thinks Davidson is right when he points out that only something that belongs to the space of reasons, the realm of norms, can play the role of a reason. But he also thinks Davidson is mistaken in saying that only beliefs can count as reasons for holding other beliefs. As I understand him, he thinks this view is wrong on at least three counts. From an epistemological point of view, coherentism cannot make room for a genuine idea of objectivity, because perception, our more immediate source of knowledge of the external world, does not play any epistemic role. Second, in traditional philosophy, belief states are usually analyzed as subjective states, i.e. as states that may be individuated independently of the external world. Thus, McDowell thinks, if one were to hold that only beliefs might count as reasons, one could hardly overcome Davidson's imagery of a 'self-contained' thinking with no bearing on external reality. Third, a picture of intentionality that does not ascribe any epistemic role to perception can hardly 
sustain the idea that mental states are about an external world. This is the basis of what McDowell terms 'minimal empiricism'. ${ }^{12}$

In order to avoid these difficulties, McDowell suggests that it is possible to conceive perceptual states in such a way that they belong to the space of reasons, although they don't have the character of beliefs. For that purpose, he thinks it is sufficient to show that perceptual states are conceptually structured. This is the core of McDowell's pre-doxastic conceptualist picture of experience.

\section{Third Step: Treatment}

As indicated above, McDowell does not present his view as an elaborate theory of experience, but just as a 'picture'. Seeing this picture as a possible outlook should promote a philosophical conversion. To a first approximation, the conceptualist claims that the content of experience is conceptual, for concepts are not only exercised at the level of judgment, but also actualized at the level of sensory intake or, in Kant's jargon, at the level of receptivity. ${ }^{13}$ McDowell thinks this move avoids the pitfall of the Myth of the Given, for it does not describe perception as a brute causal impact; it also promises to avoid coherentism, for the introduction of concepts in receptivity would dismantle Davidson's imagery of a self-contained thinking.

His hypothesis can be approached from two different perspectives. From a psychological point of view, concepts are passively actualized. From an ontological point of view, concepts should not be seen as 'epistemic intermediaries' between mind and world but as constituents of the world. Both ideas may be summed up in the thesis that perception offers an unmediated access to the world; in experience, the subject passively actualizes a battery of concepts that also play the role of constituents of reality. ${ }^{14}$

The identification of concepts with constituents of reality is the key to understanding McDowell's claim that he is in a position to offer a therapy for skepticism. He characterizes perceptual content as different from belief, because he wants to develop an alternative picture to Davidson's coherentism. ${ }^{15}$ And he identifies concepts with constituents of the world, for he is interested in preserving objectivity: the idea of passivity accommodates the requirement of an external constraint on thinking, and the idea of concepts as constituents of the world offers the mind a direct access to 'the layout of reality'.

McDowell does not provide a clear characterization of what he means by concepts as constituents of the world. In some texts, he suggests that he exploits a version of the identity conception of truth, according to which the truth of a thought does not consist in the correspondence between that thought and something different from it, but in its identity with a fact:

The point of my remarks about the identity of true judgeables with facts, in their context, is to help bring out how if we conceive experience as I have already recommended, as actualization of conceptual capacities in 
sensory receptivity, we can understand how in perception the world itself has a rational impact on our thinking. (McDowell 2005: 85; see also: 87)

In Mind and World, McDowell links his account of concepts as the constituents of thoughts with the Tractarian view of facts:

Given the identity between what one thinks (when one's thought is true) and what is the case, to conceive the world as everything that is the case (as in Tractatus Logico-Philosophicus, § 1) is to incorporate the world into what figures in Frege as the realm of sense. The realm of sense (Sinn) contains thoughts in the sense of what can be thought (thinkables) as opposed to acts or episodes of thinking. (McDowell 1994: 179; see also his 1992: 288 n 19; 2002: 134; and 2008b: 264)

McDowell emphasizes that his picture does not amount to a theory, since it merely states a 'truism' beyond dispute. However, his appeal to Frege and Wittgenstein suggests the opposite. First, Wittgenstein's view of facts is in the service of a correspondence theory of truth. ${ }^{16}$ Second, on Frege's view, the realm of reference is not made out of facts, but of things. In this sense, McDowell's picture is not a truism but a piece of constructive philosophy (I'll come back to this in section 6).

How does this putative truism provide the materials for a treatment of skepticism? The discussion above suggests that we should focus on two points: the notion of passivity and the identity between the contents of experiences and facts. Does this proposal succeed in keeping objectivity without falling prey to the Given? As indicated above, McDowell has provided two versions of this picture. The early version may be divided in two parts:

First, he suggests that a picture of perceptual content as conceptually structured may help us understand the rational transitions between perception and belief without collapsing into an inferential model. As Sellars pointed out, one of the main motivations for the Myth of the Given is the plausible idea that there is a structural difference between the way we acquire knowledge from perception and the way we acquire it from inference (Sellars 1956, § 1: 13). ${ }^{17}$ Hence, McDowell seems to think he is in a position to accommodate this insight, because he does not identify the transition from perception to judgment with an inferential move between doxastic states. Rather, he has in mind a link by 'sameness' of content. The passive actualization of concepts gives a conceptually structured content that the subject 'endorses' in perceptual judgment.

Second, McDowell not only wishes to preserve the non-inferential character of the grounding relation; he also thinks that, in so doing, he is not offering a version of the Given. He seems to sustain this view on two claims: 1) Conceiving perception as conceptual is supposed to make it 'epistemically informed'. This avoids positing a non-epistemic state as the basis of an epistemic state. 2) Seeing 
the content as conceptual seems to provide reasons. It offers reasons, for only structured entities can figure in relations of justification. ${ }^{18}$

If McDowell were right, his model would have some advantages: 1) It could keep the intuitive difference between thinking that something is the case and experiencing it to be the case, given that not all perceptual contents are endorsed in judgment. 2) This framework would not introduce a gap between experiencing and thinking, since the contents of perceptual judgments would be the same as the contents of perceptual experiences. 3) It would accommodate the intuition that perception is a non-inferential source of knowledge. 4) Since perceptionjudgment transitions are conceptual, it would provide a way out of the Given. ${ }^{19}$

So far, so good. Nevertheless, our question remains: does the above picture provide a treatment for skepticism? At first sight, characterizing the content of experiences as the same as the content of empirical judgments seems to introduce a threat of idealism. As a matter of fact, McDowell himself suggests that his view might be seen as a 'domesticated' version of Hegel's idealism, a kind of idealism that he finds innocent because it does not entail that the world is a product of the mind's activity. As our reconstruction made clear, McDowell says that the identity holds between (true) thoughts and facts, not between thinking and facts. ${ }^{20}$ Hence, he does not claim that the mind 'creates' the world by its activity of thinking, but just that, when a (true) thought is non-inferentially elicited by perception, what one thinks is a fact. This seems to preserve the intuition that the mind's perceptual access to the world is direct. Perceptual experience is 'openness to facts'.

However, it is far from clear how these ideas might lead to a conversion from skepticism. If one bears in mind that McDowell advertises his view as an alternative to Davidson's coherentism, one may wonder whether his appeal to facts has a real pay-off. My claim is that it has no real pay-off. Let me explain:

One can interpret Davidson's coherentism as an attempt to show that coherence is necessary for knowledge, and that belief is intrinsically veridical (Davidson 1990: 156). This line of thought is apparent in his rejection of epistemic intermediaries. If there were epistemic intermediaries, the possibility of knowledge would be threatened, given the skeptic's qualms about the defeasible character of perception (Davidson 1986: 144). To be sure, this is far from providing sufficient conditions for knowledge. However, Davidson expects that his argument would show that there is no reason to cast doubt on the possibility of knowledge. That's why he stresses that 'there is a presumption in favor of the overall truthfulness of anyone's beliefs' (146). A natural reading of this move is as an attempt to block the skeptic's demand of further reassurance, i.e. as a way of 'telling him to get lost' (1990: 154).

Since McDowell advertises conceptualism as an alternative to coherentism, he is committed to showing that he can do better than Davidson. Minimally, one could expect that, if conceptualism is right, there should be a presumption in favor of the overall truthfulness of anyone's perceptual beliefs. My claim is that the conceptualist appeal to facts does not satisfy this requirement. That's the main claim of the next two sections. 


\section{Using the Identity Thesis as a Therapy (I)}

To a first approximation, McDowell might be seen as suggesting that perception is factive. This fits well within the disjunctivist picture of experience. ${ }^{21}$ If I see that there is a red cube, there is a red cube. However, conceptualism provides a particular version of this claim: its strategy against skepticism is to say that there is no gap between empirical thinking and the world just because the content of perceptual judgments is the same as the content of the world. McDowell accommodates factivity by positing an identity relation between the content of perceptual experience and the facts.

How is this identity relation supposed to help? Solving this question would require further elaboration of the identity thesis. The trouble here is that McDowell insists that it is a 'truism'. Since everybody can understand it, no further elaboration is needed.

I think we could interpret part of the identity thesis if we examine the way it exploits factivity. We can summarize it as follows:

(F) If one empirically thinks that something is the case, then the content of one's empirical thinking is a fact: $T p \rightarrow p$.

Principle $(\mathrm{F})$ can be interpreted in two different ways. In a strong reading, it applies to any form of empirical thinking. In a weak reading, it is restricted to true empirical thinking.

The strong reading is obviously false. After all, experiences can mislead us. When we are misled, what we think is not the case. A natural way of making sense of this possibility is to say that subjects make mistakes when they empirically judge that things are thus and so. However, if one is interested in making room for error, one needs an account of the contents of false empirical thoughts. More generally, in order to be entitled to the weak reading, the conceptualist has to say more about perceptual error.

The conceptualist could reply that mistakes are generated in the transition from perceptual experience to perceptual judgment. One could develop this view in at least two ways: according to the common content version, perceptual experience would always present facts. Mistakes would arise at the level of judgment. According to the dual content version, perceptual experience would present either facts, or non-obtaining facts. McDowell suggests this view. In some texts, he speaks of 'misleading appearances' or 'mere appearances' as if they were an ontological category totally different from the facts presented in perception (see McDowell 1995: $407 \mathrm{n}$ 18). In other texts, he seems to suggest an opposition between two sorts of facts, obtaining and non-obtaining facts: 'If we are misled by perceptual experience, what perception purports to reveal to us as something that is the case is not something that is the case, and so is not a fact' (McDowell 2005: 85; see also his 2006 and 2008b: 264).

In what follows, I shall argue that none of these models can satisfy the following two desiderata: accounting for the possibility of error, and dissolving 
skepticism. I begin with what I take to be the more plausible view: the common content view.

On the common content view, all perceptual experiences concern facts. However, perceptual judgments can be true or false, given that not all perception-judgment transitions lead to knowledge (or true belief). The problems with this sort of view should be obvious: if perceptual judgments can be wrong, there are at least some empirical judgments whose contents differ from the facts presented in perception. This suggests that perception-judgment transitions would not be so simple a matter as endorsing the contents presented in perception. Instead, a transformation process has to take place when the mind goes from a perceptual state to a judgment. If this analysis is correct, the conceptualist is not entitled to promote his picture of experience as direct openness to facts. After all, one of the motivations to introduce it was to show that the world exerts a constraint on thinking. However, if the transition from perceiving to thinking involves a cognitive transformation of content, the mind is not directly open to facts. To be open to facts, the mind has to adopt the right attitude to them. But, why should a skeptic be confident that one usually adopts the right attitude to perceptual contents?

This point can be framed in comparison with Davidson's account. If Davidson were right, there would be a presumption in favor of the overall truthfulness of anyone's beliefs. Hence, McDowell is required to show that it is reasonable to assume that perception-judgment transitions are normally truth conducing. This is the minimum required to dispel the skeptic's demand of further reassurance. However, McDowell's picture merely shows that there are two sorts of transitions, not that truth conducing transitions are frequent enough to dispel the demand of further reassurance. In other words, he has shown that, if there are true perceptual judgments, they are open to facts. However, we wanted to know whether psychological states are, in general, open to facts.

The conceptualist might reply by arguing that, although he has failed to show that our psychological states are, in general, open to facts, he has shown that there is no gap between perceptual judgments and the world. After all, skeptics usually look for a gap in which they can insert their knife. ${ }^{22}$ But, on the identity conception of truth, if something is the case, it is the sort of thing one can think. As McDowell (2006: 229) writes, such a claim enables us 'to think we can have environmental facts directly available to us'.

However, it is hard to see how this move can dispel the skeptic's need of justification. After all, the sort of skepticism that drives Davidson's coherentism is the (putative) absence of a general presumption that belief is veridical. But there is nothing in the identity conception of truth to reinforce this presumption.

One might think that no therapy can guarantee that empirical thinking is, by nature, veridical. Trying to provide such a guarantee would require engaging with the skeptic on his own terms. But even in this reading, it is difficult to see how the conceptualist could help us dissolve the skeptical challenge. As he has it, perception-judgment transitions bifurcate into true and false judgments. Human perceptual experiences provide, so to speak, opportunities for knowledge. However, something in the picture is missing. There is no presumption that 
subjects take advantage of their opportunities for knowledge. For that purpose, one would have to tell a story of how perception-judgment transitions lead to knowledge or true belief, i.e. how falsity is excluded. However, McDowell remains silent on this count. Trying to avoid the gap between empirical thought and world, he has introduced a new gap between empirical thinking and world.

The conceptualist might try a different move. On his picture, there are two sorts of transitions: some of them lead to the True, others to the False. Hence, when one understands the picture, one thereby accepts that one can conceive of a state as having factual content. And, of course, if conceptualism shows that factive states are conceivable, there is a sense in which it entails that perceptual knowledge is possible.

The trouble with this sort of view is that it would be effective only against a very naïve form of skepticism. As far as I know, nobody has ever claimed that knowledge is not possible in the sense of not being conceivable. Actually, most skeptics grant that empirical knowledge is conceivable. This is precisely the subversive character of Cartesian skepticism. In the First Meditation, Descartes is aware that most people assume that they have perceptual knowledge. What he wants to show is that, despite their strong confidence, they could have no perceptual knowledge. He argues for this claim, not by showing that perceptual knowledge cannot be conceived but that the opposite situation is conceivable: that I might be dreaming.

To sum up, one cannot claim that conceptualism does a therapeutic job if it only shows that perceptual knowledge is conceivable. One has to show also that it is unreasonable to cast doubt on our possession of perceptual knowledge (or at least veridical perceptual belief). But, as things stand, the skeptic might still be right: although perception gives us opportunities to know, humans could be inclined not to take advantage of them.

McDowell is caught in a dilemma: if he makes room for the possibility of perceptual error, he cannot improve Davidson's therapeutic program. However, if he doesn't make room for the possibility of error, he is led to a highly implausible theory of perceptual experience.

A natural reply would be to give up Davidson's attempt to confer a presumption in favor of the overall truthfulness of anyone's perceptual beliefs. In fact, we could read some of McDowell's recent pronouncements on the skeptical challenge along these lines. In these texts, he grants the possibility of perceptual error and suggests that we should not care about skeptical scenarios: 'I hold that the way to take skepticism seriously is not to try to disprove the skeptical scenarios' (McDowell 2006: 237).

But, can this attitude really help? I don't think so. I am not saying that there should be a proof that skeptical scenarios don't obtain. What I am saying is that a good therapy should show that the conceivability of skeptical scenarios is not sufficient to take them seriously. Now, the point is that any theory of experience has to introduce two alternatives: True-leading and False-leading transitions. This is sufficient to make sense of skeptical scenarios. One has to show that, despite the existence of the two alternatives, skepticism is unreasonable. 
The conceptualist cannot improve the coherentist therapy, since he just provides a new picture of perception-judgment transitions. His room for maneuver is restricted to the new claim that perceptual intake is conceptual. This makes no real difference, since that picture does not confer a presumption of truthfulness in favor of the mind's perceptual beliefs. Even worse: the hypothesis of perception as openness to facts has no real pay-off, since coherentism also satisfies the weak demand of making knowledge conceivable. After all, it doesn't deny the platitude that sensations might lead either to true beliefs, or to false beliefs.

\section{Using the Identity Thesis as a Therapy (II)}

Let us take stock. In the previous section I objected that conceptualism doesn't improve the coherentist therapy, since it has failed to show that perceptionjudgment transitions are usually truth conducing. Furthermore, the idea that perception is openness to facts is irrelevant against skepticism, since the existence of two sorts of transitions reveals that there is some sort of transformation process from perception to judgment. This casts doubt on the original claim that perception constrains empirical thinking. Finally, one cannot envisage the therapeutic task as just aiming to show that perceptual knowledge is conceivable.

In this section, I want to go farther and show that things are even worse for McDowell. When one takes seriously his Tractarian view of the world, he has obvious problems to make room for perceptual error. Of course, McDowell grants that people make perceptual mistakes. The point is that, if his appropriation of the Tractarian ontology were right, perceptual error should be, strictly speaking, impossible.

By hypothesis, 'the world is made up of the sort of thing one can think' or, as Wittgenstein puts it, the totality of facts, not of things. Since the mind is situated in the world, when it entertains an empirical thought, that thought can only be identical to a fact. If it were not identical to a fact, the world would not be the totality of facts. But, if the world is the totality of facts, how could the mind think untruly? If it is able to think untruly, McDowell's Tractarian ontology is false.

One could try to resist this objection. In what follows, I examine two lines of reply.

First, one might argue that the ontology of facts is compatible with the idea that the mind thinks untruly. The trouble is that, when it thinks untruly, it inhabits, so to speak, a different (possible) world. The actual world is the totality of facts. When thinking untruly, the mind's thoughts concern ways the actual world might be.

But this move is implausible. Consider the following situation. Pierre is (empirically) thinking that a monster is approaching him. However, he is not seeing a monster, but his father. When we describe Pierre's situation, his empirical content a monster is approaching me differs from the true content my father is approaching me. In the actual case, he is scared; in the possible case, he 
would be confident. Different contents have different cognitive effects. However, on a Tractarian ontology, Pierre's content would not be his actual content, since the content a monster is approaching me does not obtain in the actual world. However, his psychological reaction can only be accounted for if Pierre's content is part of the actual world.

The point can be summarized as follows. On the first alternative, McDowell is led to exclude false empirical thoughts from the actual world and, consequently, to put them in a possible world. However, there is a sense in which some false contents are part of the actual world. First, Pierre's thought is causally efficacious in the actual world. Second, there is a sense in which his thought partially bears on worldly reality. After all, even if he is mistaken about the identity of the person approaching him, he is right when he infers that someone is approaching him. On McDowell's Tractarian picture, Pierre's empirical content cannot be part of the actual world. Hence, it cannot play any causal role in the explanation of his actual fright. $^{23}$

The upshot of this discussion is that, if one wants to make sense of perceptual error, one cannot merely argue, as we did, that perceptual error arises from the perception-judgment transition. This view needs ontological fixing. This leads us to the second alternative.

On the second alternative, it is necessary to patch the Tractarian picture of the world, and include non-obtaining contents. This leads us to the dual content view. As I anticipated above, McDowell seems to suggest this picture:

It is propositional content as such, not qua what is, say, seen or otherwise known to be the case, that is bipolar. [...] It is its being seen or known to be the case, not its being to the effect that things are one way rather than another, that excludes the false pole, and this exclusion cannot be in any genuine tension with the fact that things might have been otherwise. (McDowell 2005: 86)

This passage suggests that the conceptualist cannot merely say that perceptual error arises from perception-judgment transitions. He is committed to introduce a bipolar ontology in his picture of the world: if I think truly, what I think is a fact: $T_{t} p \rightarrow p$. Similarly, if I think falsely, what I think is a non-obtaining fact: $T_{f} p \rightarrow$ not-p.

The trouble here is that this solution defeats the original therapeutic project. Both Davidson and McDowell are on a par in their rejection of the skeptic's challenge to provide sufficient conditions for knowledge. But Davidson promises, at least, a general presumption in favor of the overall truthfulness of anyone's beliefs. If McDowell's ontology is right, the world is populated by nonobtaining facts. This means that getting things right is very difficult. In order to get things right, people have to be lucky enough to get attuned to the right facts. But how our minds manage to do it is something McDowell doesn't explain. He says nothing on the way perception-judgment transitions manage to exclude non-obtaining facts. 
How did we arrive at these implausible results? I think there is some lack of clarity on the role of 'intermediaries' in this story. Davidson's main reason to reject them was that the skeptic could use them to exacerbate the possibility of global defeasibility. However, the sort of unmediated access McDowell promises cannot show that this possibility is unreasonable. When one thinks truly, what one thinks is what is the case. Fair enough. The trouble here is that, as far as we know, we could be inclined to think non-obtaining facts, and skepticism looms.

Some people might think that McDowell's picture has an advantage over Davidson's. On Davidson's account, all perceptual relations are explained in wholly causal terms. Hence, even in the best cases, we are in an indirect relation to the world. By contrast, if McDowell's picture is right, it depicts the good cases as bearing a more direct access to the world.

This line of reply leaves me unmoved. On the one hand, the aim was to eliminate epistemic intermediaries, not causal intermediaries. Even if one endorses McDowell's view, one has to assume that causal processes mediate our perceptual contact with the world. So, in that respect, all theories are on a par (see Campbell 2002: chapter 6). The only way of taking some extra benefits of McDowell's view would be to eliminate causal intermediaries as well, but this would lead to an extravagant position.

On the other hand, there is some reason to think that a coherence theory can provide a better account of perceptual error. As Davidson points out in the Introduction to Subjective, Intersubjective, Objective, 'to perceive that it is snowing is, under appropriate circumstances, to be caused (in the right way) by one's senses to believe that it is snowing by the actually falling of snow' (2001: xvi). This picture allows for the possibility of truth and falsity, as McDowell's amended picture should allow. Nevertheless, conceptualism can accommodate perceptual error only by advocating a dubious bipolar ontology where the world is populated by obtaining and non-obtaining facts. By contrast, if coherentism is right, perceptual error can be explained in terms of the subject's doxastic attitudes. Being perceptually mistaken results from the subject's taking that things are thus and so when they are not thus and so. ${ }^{24}$

These arguments show that conceptualism doesn't provide the therapeutic benefits it promised. McDowell advertises his framework as an alternative to coherentism. Since Davidson's worry with skepticism concerns the possibility of knowledge, it is clear that McDowell's conceptualism has no means to improve Davidson's therapy. McDowell's view can only work on the assumption that the world has obtaining and non-obtaining facts. This is the sort of side-effect one should avoid when one prescribes a treatment.

\section{An Externalist Response?}

The arguments so far may be seen as providing indirect support for the claim that beliefs are the minimal units of justification. If conceptualism cannot improve the coherentist therapy, there is no reason to give up Davidson's claim that nothing 
can count as a reason except another belief. In this section I shall exert some pressure on the second claim: as far as skepticism is concerned, there is no reason to deny that perception has non-conceptual content. For that purpose, I shall focus on the nature of perceptual entitlement.

Let us assume that the conceptualist can show that there is a presumption of truthfulness on perceptually based judgments. Then, the question arises: how does my perceptual experience of $p$ entitle me to hold $p$ ? The response to this question depends on one's methodological commitments and the way one interprets the skeptical challenge: does the skeptic ask for internal reasons that I am not a brain in a vat? Or does he ask for external reasons purporting to show that I am not a brain in a vat?

These questions are tricky. When one frames the discussion in these terms, the line between engaging with the skeptic on his own terms and prescribing a therapy becomes thin. However, one can describe the skeptical challenge either as internalist or externalist, in order to see what sort of therapy is required. If one reads conceptualism as a picture of first-person experience, it should be possible to use it as a therapy against internalist skepticism. But, if it is taken as a hypothesis put forward from the theorist's point of view, it could also deliver a therapy against externalist skepticism.

From an internalist viewpoint, the conceptualist can argue that, in ordinary contexts, the subject is aware of his experience of $p$ as entitling him to believe that $p$. This awareness should be sufficient to show that it is unreasonable to ask for further evidential support. From an externalist point of view, perceptual experience would provide the subject with a direct access to the world, although he would not be in a position to rule out skeptical scenarios just by considering the character of his experiences. Let us explore the merits of each proposal.

From an externalist point of view, one can stipulate that perception-judgment transitions are structured in such a way that perceiving (normally) yields knowledge (or true belief). Many people follow this path. They argue that, although perception is defeasible, it is reliable enough to yield true belief, warranted belief or knowledge. Another approach, advocated by disjunctivism, takes it that perceptual states ground perceptual beliefs because their structure differs from that of hallucinatory (or illusory) states. According to some influential versions of disjunctivism, perceptual states must be individuated by the (true) facts they present and not by mental episodes that fall short of facts. By parity of reasoning, if a subject is in a perceptual state, his perceptual beliefs are warranted, even though he does not know whether he is in a perceptual, or in a hallucinatory state. ${ }^{25}$

The present proposal suggests that conceptualism promises a compromise between epistemic internalism and externalism: it ascribes accessible reasons to the subject, but it does not provide her with access to the factivity of her reasons. As Pritchard (2008: 287 n 8) puts it, conceptualism so understood introduces a picture where one 'only needs reflective access to the supporting grounds for one's belief and not also to the fact that they are supporting grounds'. (For a similar view, see Brewer 1999: 100 n 6.) 
Suppose one favors a solution along these lines. In this case, one may wonder whether it really coheres with the conceptualist view of epistemic justification. If one recognizes that the 'goodness' of the reasons provided by perception is justified from the theorist's viewpoint, this undermines the motivation to conceive experience as conceptual. Recall that McDowell condemns theories of non-conceptual content, since they provide 'exculpations' when we want 'justifications'. However, if the subject has no reflective access to the factivity of her reasons, there is a clear sense in which experience provides her exculpations, instead of justifications.

One could reply that the demands of responsibility are lower in ordinary contexts. If there are no reasons for doubt, the subject is entitled to take her experiences at face value, even though he has no access to the 'goodness' of the reasons they provide. But this reply would miss the target of the present argument. Of course, any theory of perceptual experience should find a compromise between internalist and externalist intuitions (see Dretske 2000: 601). The trouble here is that there is no reason to take the conceptualist compromise as the only possible one. A non-conceptualist can challenge it by saying that he could find a different compromise position between internalist and externalist intuitions. Let me develop the point in some detail.

When one inquires whether a particular content, say $p$, may count as a good reason, one has to adopt an external point of view on $p$. If I ask whether my perceptual experience of $p$ provides me a good reason to think that $p$, in so doing, I implicitly place myself at a vantage point external to my perceptual experience. If I doubt whether I am seeing a red wall in front of me, it will not help me to consider the intrinsic features of experience. To decide whether I am seeing a red wall in front of me, i.e. whether experience provides me good reasons, I have to consider aspects external to it, like the lighting conditions, whether my visual system is working properly, and so on. At that point, my epistemic position is not the same as the epistemic position I was in before I raised the doubt.

The critical point here is that a subject can only appreciate the 'goodness' of a reason $p$ by occupying an external point of view on $p$. If this is so, it seems superfluous whether this reason is conceptual or not, or whether it is accessible to the subject of experience or not. Its 'goodness' as a reason is independent of its conceptual character. Its conceptual character is designed to make it accessible to the subject, whereas its 'goodness' is a matter of assessing it from an external viewpoint. Hence, one might take perceptual content as non-conceptual. One might take it as accessible to the subject only at the level of judgment. And her epistemic appraisal of her judgments would involve the perspectival shift we all need when we examine whether a reason is a good reason.

The upshot of the discussion is two-fold: if the only argument to introduce conceptual contents is to avoid introducing exculpations instead of justifications, it won't do. Everybody needs, at one moment or the other, to be exculpated by introducing an externalist ingredient in epistemology. If one aims at finding an epistemological compromise between internalist and externalist intuitions, it is 
possible to accommodate them within a theory of non-conceptual content, where the 'goodness' of reasons is assessed at the level of judgment.

On the face of it, McDowell might try another solution. Instead of providing an externalist picture that entails that perception is a source of good reasons, he could attempt to show, from inside, that it is reasonable to think that experience normally offers good reasons. He could do it by conceiving of experiences as having a self-authenticating character. When I am in a good case, experience somehow 'displays' its entitling character.

There are ways of construing this claim without relapsing into the Myth of the Given. One of the hallmarks of perceptual experiences is that they present their objects as being 'there'. Ordinary subjects don't take their experiences as if they were copies or reproductions of objects. Instead, they feel that objects are immediately present. One might take the feeling of presence as (partially) explaining the entitling character of perceptual experiences (see Pryor 2000).

I think this line of reply has some merits. However, there are two objections against it. First, there is no direct connection between the conceptualist picture of experience and the entitling role of perceptual presence. Second, it is difficult to see how phenomenology could be used as a therapy for skepticism about the possibility of knowledge. As Wright (2002) points out, a pervasive characteristic of skeptical scenarios is that they introduce undetectable changes in the epistemic context: one is asked to imagine mules cleverly disguised as zebras, brains-invats whose experiences are indiscriminable from experiences of an external world or people dreaming while asking whether they are awake. The therapist should work harder to dispel the prima facie plausibility of these cases. He should show that, although these cases are conceivable, there is no reason to take these possibilities as nearby possibilities.

\section{Intuitive Conceptual Content?}

In recent writings, McDowell (2007, 2008a) has introduced a new way of developing conceptualism. This new account reveals continuities with some suggestions presented so far, but also crucial discontinuities. As our arguments made clear, it is necessary to make room for perceptual error, without incurring a dubious ontology of non-obtaining facts. In his recent view, McDowell introduces a distinction between the content of perceptual judgments and the content of experiences. This makes the possibility of error more vivid. However, the new picture rejects the old assumption that perceptual content is propositional, threatening the anti-skeptical application of the identity conception of truth.

As far as I know, McDowell does not motivate his new view by invoking the sort of arguments presented here. However, the new picture has the potential of avoiding some of the worse aspects of the Tractarian ontology. If the contents of the world are not propositional, one is not forced to introduce non-obtaining facts. After all, one can conceive of the world as the totality of things, not of facts. The trouble here is that, as far as I understand him, McDowell seems to think that

(c) 2009 Blackwell Publishing Ltd. 
his new view is still compatible with the identity thesis, partly because he thinks it is a truism (see, e.g. his 1995: 402 n 10, 407 n 17; 2008a: $§ 1$ and 2008b: 247). In what follows, I shall suggest that, although the new picture is better than the original one, it cannot be used as a therapy for skepticism.

McDowell credits this new picture to Kant's notion of intuitive content. On this view, there are two levels of conceptual content: first, in perceptual experience, concepts are actualized in a non-propositional way. Intuiting amounts to a 'having in view'. McDowell borrows Kant's idea that intuitions do not provide a sheer multiplicity, but have some sort of formal unity. In the case of vision, he hypothesizes that experiences draw 'on conceptual capacities associated with concepts of proper and common sensibles' (McDowell 2008a: 4). He is not quite explicit on the nature of this unity. However, he argues that the sort of unity provided by intuitions is conceptual, despite its non-propositionality. By contrast, perceptual judgments would have a propositional content. This content would involve the exercise of more specific recognitional concepts.

McDowell introduces the new picture by considering the following case. Suppose I form a perceptual judgment I would express by uttering the sentence 'That's a cardinal'. In this case,

... my experience makes the bird visually present to me, and my recognitional capacity enables me to know noninferentially that what I see is a cardinal. Even if we go on assuming my experience has content, there is no need to suppose that the concept under which my recognitional capacity enables me to bring what I see figures in that content. (McDowell 2008a: 3)

On this picture, McDowell accommodates the non-inferential character of perception-judgment transitions, not by means of an identity relation but by a different kind of process. He envisages two sorts of scenarios. In some cases, the discursive activity makes some of the contents already present in the intuition explicit. In other cases, the discursive activity goes beyond the intuition. However, in both scenarios, 'the entitlement derives from the presence to one of the object itself, not from a premise for an inference, at one's disposal by being the content of one's experience' (McDowell 2008a: 12).

This model can be illustrated by our previous example. If I were to utter the sentence 'That's a bird', my statement would make the content of the intuition explicit. I would be entitled to my judgment just because the concept bird was already actualized in the intuitive content. By contrast, if I were to utter the sentence 'That's a cardinal', my judgment would go beyond the content of the experience and, hence, it would be grounded, only in part, on the content of intuition. The probability of perceptual error would be conditional on the potential mismatches between the intuitive content and the exercise of recognitional concepts. Clearly, the probability of being mistaken by uttering the sentence 'That's a cardinal' would be higher than the probability of being mistaken by uttering 'That's a bird'. 
I think this sort of model provides some insights, as I explain elsewhere. ${ }^{26}$ However, this picture can only be validated if there is a principled way of drawing the line between intuitive contents and the contents of judgment. Strictly speaking, there is no reason to take the concept bird as the content of experience. That's why, when one presses the point, the conceptualist is led to conceive of the content of intuition as including only concepts of proper and common sensibles: shape, size, position, movement or its absence. 'We think of common sensibles accessible to sight as including, for instance, postures such as perching and modes of locomotion such as hopping or flying' (McDowell 2008a: 5).

If one makes this move, it becomes less clear how the new model could be used as a therapy for skepticism. If there are intuitive conceptual contents, there are not two cases, but only one: our perceptual judgments always go beyond intuitive contents. Ordinary perceptual judgments are not of the form that moving object is thus and so', but of the form 'that's a bird', 'that's a cardinal', 'that's my pet', etc. If intuitive contents only actualize concepts of common and proper sensibles, all perception-judgment transitions have to enrich the content presented in intuition. Ordinary judgments do not consist in making something explicit. They involve, rather, a construction process.

This is bad news for skepticism. The skeptic is worried about the possibility of perceptual error. If $\mathrm{McD}$ owell is right, there is a sense in which all perceptual judgments are wrong, since all perceptual judgments go beyond intuitive contents. Perceptual judgments involve the exercise of concepts that are not 'given' in experience.

In order to resist this conclusion, one would have to introduce a new ontological level. One might draw a line between the object cardinal, the content of intuition and the concept cardinal. But this would lead us too far from the therapeutic strategy delineated before. McDowell has insisted for many years that the identity conception of truth is a truism: when I see that $p$, then $p$. On the new account, this putative 'truism' is obviously false when applied to perceptual experience. Strictly speaking, I cannot see that $p$, since the content of perception is intuitive, not propositional. What I can do is judge that $p$. If one is optimist, one can take this picture as making room for a relation of correspondence. One can conjecture that being shaped so and so stands in a many-one relation to being a bird, and being a bird stands in a many-one relation to being a cardinal, etc. If the content of perceptual judgments does not figure in intuitive content, one needs a transformation process to go from perceptual states to perceptual judgments.

The trouble is that this picture makes facts inaccessible to cognition: in order to be open to facts, the subject would need direct access to them. If the subject only has conscious access to facts by thinking that thus and so, he does not have direct access to facts. Facts are rational elaborations of reality. Reality is given in intuition, but conscious access starts at the level of judgment. This was Davidson's (1986: 142) point when he insisted that being aware of a sensation 'is just another belief'. It doesn't matter whether one takes the materials for this awareness as conceptual. The point still applies: since intuitive content is not accessible qua intuitive content, skeptics obsessed with defeasibility shall 
find no relief in a picture that posits an intuitive content as the rational basis of judgment.

Let me develop this point in a different way. McDowell's aim of conceiving concepts and intuitions as intrinsically related is valuable. I myself take it as an adequacy requirement for any theory of perception. However, it is misleading to paraphrase intuitive content as a 'having in view'. If McDowell's picture of intuitive content is right, it cannot be a having in view, i.e. it cannot reflect our phenomenal access to the world. Ordinary visual experience is not merely about shapes, positions or movements. Intuitive content is rather introduced as a hypothesis from the third-person point of view. If intuitive concepts described the first-person perspective, it would be easier to understand what McDowell means by 'intuitive content', and one would expect to find a widespread consensus on the matter. However, it is not clear which concepts are part of the contents of experience, and which are part of the content of perceptual judgments. If it were obvious, it would be hard to explain why McDowell took the content of experiences to be propositional for so many years.

This line of reasoning suggests that, if McDowell is right on the nature of intuitive content, we have to give up the picture of perceptual experience as direct access to facts. Perceptual experience is not open to facts, because propositionality is available only at the level of judgment. This lack of directness leads us to the starting point: how is perceptual knowledge possible? If perceptual knowledge is factive, perceptual knowledge is not possible unless there are facts accessible to perceptual judgments. But intuitive content, lacking propositional structure, does not provide facts. Hence, perceptual knowledge needs something that intuitive contents cannot provide. Bad news for skepticism ...

\section{Fallibility, Disjunctivism, and Conceptualism}

One might argue that the arguments presented above rest on a misunderstanding of the skeptical problem. I have assumed so far that, for McDowell's therapy to improve Davidson's treatment, it should show that there is a standing presumption in favor of the truth of our perceptual beliefs. However, this assumption seems to rest on the claim that skepticism arises from our fallibility alone. As a referee for this journal pointed out to me, 'that one may on any particular occasion be unknowingly in error does not entail that we lack beliefs which are on the whole true and which on the whole amount to knowledge'. With this diagnosis in mind, 'McDowell's idea is to show how, in the "good" case, one's perceptual experiences can be such as to give us the kind of reflectively accessible factive rational basis for our beliefs which would suffice for knowledge'. As a result, his therapy:

... doesn't deny that agents cannot distinguish between the good case and the parallel 'bad' case (in this sense the fallibility remains), but his claim is precisely that we should not let the bad case determine the 
epistemic support that our beliefs enjoy in the good case. Thus, contra the skeptic, there is no standing reason to suppose that knowledge is impossible, since McDowell's approach has shown how it is in fact possible; indeed, how paradigmatically it is possessed.

As I understand the present objection, it is based on two points: the role of fallibility in the diagnosis of the skeptical problem, and a tacit conception of what a satisfactory treatment should provide.

Concerning the first point, I think we could distinguish between subjective fallibility and objective fallibility. To a first approximation, the former is related to the agent's capacity to know whether she is in a good or in a bad case, only by exploiting cognitive resources available to her from her point of view (e.g. reflection, memory, inference, etc.). By contrast, the latter notion is related to the question whether, as a matter of fact, a subject is in a good or in a bad case; to put it differently, the question is whether she actually knows the external world, or is capable of knowing it, independently of whether she is in a position to know that she knows it.

Concerning the second point, it is possible to distinguish McDowell's line of argument in his well-known papers on disjunctivism from his line of argument in his conceptualist view of perceptual experience. Although both lines of argument bear interesting relations to each other, and McDowell tries to harmonize them, they are potentially dissociable. In this paper I was mainly interested in the latter line of argument, i.e. in the potential of conceptualism to dissolve skepticism, and not in the disjunctivist account of perceptual experience. However, I also think some of the points made earlier also apply against the latter strategy. Let me explain.

McDowell's disjunctivist strategy against the skeptic rejects the Cartesian idea that, for knowledge to be possible, the agent should be subjectively infallible. I think McDowell rightly emphasizes that this line of thought presupposes a contentious view of the mental as an autonomous realm completely transparent to the subject. (See McDowell 1982: 389-390 and 1986: 236-237, 240.) As he points out, it would be 'epistemologically disastrous-to suppose that fallibility in a capacity or procedure impugns the epistemic status of any of its deliverances' (1986: 232). These two remarks make it possible to develop a disjunctivist account of experience, according to which the subject can be in a good case even though she cannot tell whether she is in a good or in a bad case.

As I see it, my requirement of a presumption in favor of the truth of our perceptual beliefs doesn't require any sort of subjective infallibility. This requirement is just formulated from the theorist's point of view. In Davidson's case, the putative presumption in favor of the overall truth of our belief systems is a conclusion he reaches from an external point of view, i.e. by developing a philosophical account of belief. As McDowell (1994: 16) acknowledges, Davidson tries to ground this conclusion by connecting belief with interpretation, and urging that it is in the nature of interpretation that an interpreter must find her subjects mostly right about the world with which she can observe them causally 
interacting'. This is an externalist move: Davidson does not claim that ordinary agents have a direct access to the veridicality of their beliefs.

In McDowell's case, it is possible to formulate the same requirement from an external point of view. Assuming that there are two sorts of perception-judgment transitions, why should the skeptic grant that perception leads to true judgments? Why shouldn't he claim, for instance, that only $1 \%$ of our perception-judgment transitions lead to the True? As far as I can see, this sort of reply is orthogonal to the quality of the subject's first-person access to the factivity of her own mental states. After all, the arguments presented above don't exploit the subject's inability to know which disjunct, the True or the False, is in question. The aim of the arguments was rather to show that, on McDowell's conceptualist picture(s), it is not clear how there can be factive cognitive states. This point is easily overlooked when one focuses on the formulation of the disjunctivist picture as presenting two possibilities. The bulk of the paper is to show that one has to earn the entitlement to talk about the two disjuncts, instead of assuming that subjects are usually led to the True.

This leads us to the second point. The objection assumes that it is sufficient to depict two sorts of cases, as the disjunctivist has them, in order to show that knowledge is in fact possible. However, what I have said so far suggests the opposite view. As I explained in the analysis of the therapeutic program, the therapist purports to earn the right not to worry about traditional problems in two steps: first, he diagnoses the skeptical problem by spelling out its assumptions. (See McDowell 1994: 142 n 17, 155 n 30.) Second, he tries to earn the right not to worry about skepticism by providing a treatment, i.e. by sketching an alternative picture where the original worries disappear. I think McDowell fails in the latter task because he mistakenly assumes that the root of the problem of knowledge is the same as that of the issue of how content is possible. But, if my arguments are right, the problem of skepticism is not merely a problem of content. It is also related to the sorts of processes that lead to knowledge. When one inquires into the details of McDowell's account of perception-judgment transitions, the old worries reappear and the putative entitlement not to worry about traditional problems is revealed as illusory. That's why I think disjunctivism cannot fully earn the right not to worry about skepticism. One cannot just assume there are two possibilities, True-conducing and False-conducing transitions. A story must be told about the way falsity gets excluded in the transition from perception to judgment. But, as I argued at length, McDowell's conceptualism doesn't succeed in that task.

One can put the point in the following way: the disjunctivist account of experience can be seen as stating the form of a treatment of skepticism. That's why it can be dissociated from McDowell's conceptualist framework. As McDowell (1995) puts it, in the good case we are cognitively presented with facts. The disjunctive strategy works against a skeptic that is ready to grant that there is an adequate conception of perception-judgment transitions. However, if one is faced with a skeptic that inquires into the nature of these transitions, the therapy must be completed. Here is where conceptualism comes into scene. It is 
introduced as an account of the way human understanding 'interacts' with sensibility, i.e. as a picture of the perceptual content underlying perceptual judgment. The trouble here is that the conceptualist proposals don't entitle us to state the True side of the disjunction. The disjunction assumes that a 'cognitive purchase on an objective fact' (McDowell 1995: 402) is possible. But this is precisely what I have tried to question. One cannot merely stipulate that a cognitive purchase on an objective fact is possible. If one is providing a picture of perception-judgment transitions, one has to show how it makes a cognitive purchase on an objective fact possible.

McDowell is right that such a cognitive purchase is not possible if one has a Cartesian view of mind, where reasons are conceived as internal. However, my point is that such a cognitive purchase is not possible either, if one holds a conceptualist view of perception-judgment transitions. McDowell's program can be seen as combating the Cartesian picture where truth and world are external to the mind (McDowell 1982: 390-391). My point is that getting rid of that view is not sufficient. One also needs an adequate theory of how perception and judgment are connected with each other. ${ }^{27}$ Why do I think that he hasn't succeeded in that program? Let me summarize some of the arguments presented here:

The radical separation between thinking and content makes the grasp of the right facts difficult to understand. Facts are external to the exercise of concepts in judgment. However, what one needs to be in a good case is to have facts accessible to judgment. This becomes clear when one realizes that knowing is a propositional attitude and, as a result, it is not sufficient to conceive of perception as openness to facts. One also has to tell a story about the way these perceptually presented facts reach thinking.

However, things get messy when one takes seriously the suggestion of introducing non-obtaining facts (or 'mere' appearances) in the world, in order to make sense of perceptual error. If the mind is located in a world that is populated by non-obtaining facts (or 'mere' appearances), the possibility of getting things right rests on sheer luck. Here I should not be interpreted as claiming that epistemology should restrict itself to a luck-free zone. (See McDowell 1995: $406 \mathrm{n}$ 15.) Instead, what I mean is that one's framework should not generate additional requirements of epistemic luck. As McDowell has taught us, dualistic frameworks exacerbate the need for additional favors from the world. If perception provides either facts or non-obtaining facts, one requires additional luck to get knowledge. The point here is not that we should look for a luck-free zone, but instead conceive of perception-judgment transitions in a non-dualistic way, in order not to require an additional amount of good fortune. ${ }^{28}$

Even if the reader doesn't find these objections persuasive, he should take seriously the incompatibility of the original anti-skeptical strategy with McDowell's more recent views on intuitive conceptual contents. The problems this picture presents can be easily generalized to any transformational account of perception-judgment transitions. These pictures cast doubt on the ontology of facts, given that they threaten the seemingly 'commonsensical' identity thesis. 
Any transformation model is committed to a correspondence theory between different levels and, as a result, it cannot guarantee that facts be directly accessible to cognition. Moreover, if one's view entails that propositionality is available only at the level of judgment, it is not clear how there could be perceptual knowledge. This point is crucial in the light of McDowell's earlier contention that, in order to have perceptual knowledge, facts themselves must be given as the justifiers of our cognitive attitudes.

\section{Final Remarks}

Skepticism about the possibility of knowledge is usually based on the possibility of introducing skeptical scenarios. Philosophers usually take the exclusion of these scenarios as necessary to refute it. In the present article, I took for granted that, even if we cannot meet that standard, we can show that skeptical scenarios are not nearby possibilities. That's why I asked whether conceptualism could do better than Davidson and argued in favor of a general presumption that perceptual beliefs are veridical.

My conclusion is that conceptualism fails on this count. The best thing it can do is show that perceptual processes bifurcate into true and false judgments. The trouble is that this was already provided by doxastic theories of justification. Furthermore, doxastic views have a further merit: they don't introduce nonobtaining facts. In this sense, there are good reasons to keep Davidson's claim that belief states are the minimal units of justification.

On the other hand, careful examination suggests that any account of perception-judgment transitions has to introduce different levels of analysis. They are required to make room for the possibility of perceptual error and to find a compromise between internalist and externalist intuitions. The defender of nonconceptual content could press this point in support of his cause.

It should be stressed that I am sympathetic to a reaction to skepticism along the lines indicated above, i.e. a rejection of some tacit assumptions of the skeptical challenge. My point is that McDowell provides a wrong diagnosis of skepticism; this leads him to provide the same treatment both for a picture based on a questionable scheme-content dualism and a picture that casts doubt on the possibility of knowledge.

McDowell is certainly right when he reacts against Davidson's imagery of thinking as a self-contained game, as when he claims: 'we can't get outside our skins to find out what is causing the internal happening of which we are aware' (Davidson 1986: 144). This suggests that we cannot get outside our beliefs (McDowell 1994: 16). It is clear that we do not need to get outside our skins to reach the world. It is by being in our skins that the world is available to us. But these remarks are inessential to the main points Davidson makes. What drives him is the aim of showing that we are not obliged to justify all our beliefs. We can trust them. Thus, I assume that McDowell was misled by the self-containment imagery. 
I hope the arguments presented here provide support for the project of reconciling the theory of perceptual entitlement with Davidson's claim that 'nothing can count as a reason for holding a belief except another belief'. His dictum does not entail that human thinking is a self-contained game. One can attempt to rehabilitate that insight by conceiving of perceptual beliefs as the minimal units of justification. One could try to endow them with a presumption of being right by showing that they are intrinsically related to non-conceptual perceptual processes. Of course, when one attempts to specify this connection, it becomes plausible to conceive of belief systems as integral parts of embodied beings that exploit non-conceptual abilities in their perceptual relation to the world. ${ }^{29,30}$

\section{Santiago Echeverri}

Institut Jean-Nicod (CNRS-EHESS-ENS)

Pavillon Jardin-École Normale Supérieure

France

santiagoecheverri@hotmail.com

\section{NOTES}

1 Wright $(2002,2008)$ doesn't seem to distinguish the therapeutic project from the dogmatic one. Pryor (2000: 517) also conceives of dogmatism as having a therapeutic aim.

2 'But let me remark that my move is not well cast as an answer to skeptical challenges; it is more like a justification of a refusal to bother with them' (McDowell 1995: $408 \mathrm{n}$ 19; see also his 2006: 235). The term 'dogmatism' is unfortunate, since it is usually taken to preclude criticism.

${ }^{3}$ This is not the only motivation in McDowell's writings. In other papers, he has insisted that his conceptualist picture of experience would offer an adequate approach to intentionality. I criticize this version of conceptualism in Echeverri (submitted).

${ }^{4}$ My point can be captured in a different way: the theory of content should remain dogmatic concerning skepticism.

${ }^{5}$ A prominent example is to be found in Kant, who distinguishes intuitions from concepts. Sellars' case is also clear: whereas he thinks that intentionality is languagedependent, he urges the introduction of 'sense impressions' as theoretical entities. See Sellars 1956, 1968. For a critique of McDowell's interpretation of Sellars, see: DeVries 2006, and McDowell's 2008b reply.

${ }^{6}$ See also McDowell 1986: 259; 1995: 409. In many writings he suggests a double reading of conceptualism: 'And surely there must be such grounding if experience is to be a source of knowledge, and more generally, if the bearing of empirical judgements on reality is to be intelligibly in place in our picture at all' (1994: 5). See also 1994: 6, 15, 66. In other texts, McDowell labels his view 'transcendental' and emphasizes that it would put an end to traditional obsessions with skepticism. See McDowell 1998a: 366.

7 I am indebted here to Dodd's (2000: $78 \mathrm{n}$ 11) illuminating discussion.

8 I sketch that picture in Echeverri (in preparation).

${ }^{9}$ See also: '[I]f one attributes epistemological significance to what is given in experience, so conceived, one tries to construe as a justification what could be at best be an exculpation' (McDowell 1998a: 365).

(c) 2009 Blackwell Publishing Ltd. 
10 The view of perceptual normativity in terms of 'accuracy' or 'correctness' is endorsed by Peacocke $(2001,2004)$ and Burge (2003). However, they also introduce a reliability requirement of belief-formation. Brewer (2006) and Gaskin (2006) interpret McDowell's emphasis on normativity in terms of 'accuracy' or 'correctness'. If they were right, McDowell's insistence on conceptualism as a way of introducing normativity would be ill motivated. For an analysis of the conceptualist picture of normativity, see Echeverri (submitted).

${ }^{11}$ In fact, many critics think that one could counter McDowell's argument by advocating a form of externalism. This response cannot satisfy the conceptualist picture of normativity. In a recent text, McDowell (2008a: 13) acknowledges the 'internalist' orientation of this line of argument.

12 'That is what I mean by 'a minimal empiricism': the idea that experience must constitute a tribunal, mediating the way our thinking is answerable to how things are, as it must be if we are to make sense of it as thinking at all' (McDowell 1996: xii). In his 2003: 158-59, McDowell provides further arguments against Davidson's view. I examine them in Echeverri (in preparation).

13 Brewer $(1999,2005)$ defends a similar view. Both theories differ from Noë's 1999 conceptualism, since he introduces concepts at the level of judgment. For a recent pronouncement on the pre-judgmental actualization of concepts, see McDowell 2008b: 228-ff.

${ }^{14}$ For a discussion of this aspect of McDowell's view, in relation to Jennifer Hornsby's developments of the identity conception of truth, see Dodd 2000: 174-86.

15 McDowell (1994: 144) acknowledges this point.

16 See Wittgenstein 1921: 2.173, 2.21, 2.221, 2.222, 2.223, 4.05, 4.06.

17 The main difficulty is to preserve the non-inferential character of perception without falling in a version of the Myth. However, not all theorists understand immediacy as synonymous with non-inferential. See Pryor 2000: 524-25.

18 This condition is dropped in McDowell's more recent formulation of conceptualism. This has some negative implications for the anti-skeptical project, as I argue in section 7.

${ }^{19}$ For a critical analysis of these claims, see Echeverri (submitted).

20 'It is central to Absolute Idealism to reject the idea that the conceptual realm has an outer boundary, and we have arrived at a point from which we could start to domesticate the rhetoric of that philosophy' (1994: 44; see also 1996: ix). 'A thought, in Frege's sense, is what one thinks (or says) if one thinks (or says) something, as opposed to the thinking of it' (McDowell 2005: 83; see also the discussion in: 2002). McDowell's commitment to a form of idealism has been denounced by many critics: Friedman 1996, Engel 2001 and Dingli 2005: 58,63 .

${ }^{21}$ See McDowell 1982, 1995, 2005: 86. For a critical assessment of this view, see Pritchard 2003. I'll try to be more explicit on the relation of conceptualism to disjunctivism in section 7 .

${ }^{22}$ I owe this formulation to Evans 1982: 225.

${ }^{23} \mathrm{I}$ am indebted to Jérôme Dokic for pressing me on this point.

${ }^{24}$ Dokic (2000, forthcoming) examines the effects of including bipolar states of affairs in the world. In a similar vein, Dodd (2000: 111-14) has emphasized that facts cannot be in the world, since that would preclude their possibility of being false. He also provides a well-documented discussion of the main motivations to declare non-obtaining facts as entia non grata (162 ff). This explains, to some extent, Dodd's defense of what he terms a 'modest identity theory', a picture that presupposes a clear-cut distinction between the realms of sense and reference. My critique of the identity thesis is slightly different. I claim

(C) 2009 Blackwell Publishing Ltd. 
that, even if there were bipolar contents, one should show that perception-judgment transitions are normally truth conducing. Given that McDowell (2005: 87) himself takes reflection on truth for its own sake as 'not particularly relevant' for his argument, the present line of attack should be more pressing for him.

25 See McDowell 1986, 1995, and Evans 1982: chapter 6. For a critical analysis of the arguments in favor of disjunctivist theories of perception, see: Brewer 1999: $229 \mathrm{ff}$. and Dokic 2001.

${ }^{26}$ See Echeverri (in preparation).

27 'If moves in the space of reasons are not allowed to start from facts, riskily accepted as such on the basis of such direct modes of cognitive contact with them as perception and memory, then it becomes unintelligible how our picture can be a picture of a space whose positions are connected by relations reason can exploit, such as that one of them is a reliable ground for moving by inference to another' (McDowell 1995: 409-410; emphasis mine). In 1995: 402, McDowell explicitly introduces the requirement of 'a cognitive purchase on an objective fact'.

28 As McDowell (1995) rightly emphasizes, everybody has to acknowledge that, in the good cases, 'the world does one a favor'. However, if the world is populated both by obtaining and non-obtaining facts, it is not clear how the world can do us the favor of connecting our perceptual judgments to the right facts.

${ }^{29}$ I introduce this picture in Echeverri (in preparation).

${ }^{30}$ I presented a first draft of this paper at the University of Munich ( $8^{\text {th }}$ February 2007). I am indebted to professor Carlos U. Moulines and the audience of his graduate seminar for raising a number of questions. Jérôme Dokic, Reinaldo Bernal, and Felipe Carvalho read a second draft and discussed some parts of the paper. I hope their useful comments led me to improve it. I am also grateful to an anonymous referee who provided me with valuable comments, which led me to write section 7 .

\section{REFERENCES}

Brandom, R. (1998), 'Perception and Rational Constraint', Philosophy and Phenomenological Research, 58: 369-374.

Brewer, B. (1999), Perception and Reason. Oxford: Oxford University Press.

- (2005), 'Do Sense Experiential States Have Conceptual Content?', in E. Sosa and M.

Steup (eds), Contemporary Debates in Epistemology. Oxford: Blackwell.

(2006), 'Perception and Content', European Journal of Philosophy, 14: 165-81.

Burge, T. (2003), 'Perceptual Entitlement', Philosophy and Phenomenological Research, 68: 50348.

Campbell, J. (2002), Reference and Consciousness. Oxford: Oxford University Press.

Davidson, D. (1982), 'Empirical Content', Grazer Philosophische Studien, 16-17: 471-89. Reprinted in Davidson 2001: 159-75.

- (1986), 'A Coherence Theory of Truth and Knowledge', in E. LePore (ed.), Truth and Interpretation: Perspectives on the Philosophy of Donald Davidson. Oxford: Blackwell: 30719. Reprinted in Davidson 2001: 137-53.

— (1990), 'Afterthoughts', in A. Malachowski (ed.) Reading Rorty. Oxford: Blackwell: 134-

8. Reprinted in Davidson 2001: 154-8.

- (2001), Subjective, Intersubjective, Objective. Oxford: Oxford University Press.

DeVries, W. A. (2006), 'McDowell, Sellars, and Sense Impressions', European Journal of Philosophy, 14: 182-201.

(c) 2009 Blackwell Publishing Ltd. 
Dingli, S. M. (2005), On Thinking and the World: John McDowell's 'Mind and World'. Aldershot: Ashgate.

Dodd, J. (2000), An Identity Theory of Truth. Basingstoke: Macmillan.

Dokic, J. (2000), 'Perception as Openness to Facts', Facta philosophica, 2: 95-112.

- (2001), L'esprit en mouvement: essai sur la dynamique cognitive, Stanford, CSLI (Center for the Study of Language and Information).

— (forthcoming), L'esprit (bipolaire) et le monde (vérifacteur): Quelques réflexions sur L'esprit et le monde de John McDowell', Philosophiques.

Dretske, F. (2000), 'Entitlement: Epistemic Rights without Epistemic Duties?', Philosophy and Phenomenological Research, 60: 591-606.

Echeverri, S. (submitted), 'The Myth of the Conceptual Given'.

- (in preparation), 'A Doxastic Account of Perceptual Experience'.

Engel, P. (2001), 'The False Modesty of the Identity Theory of Truth', International Journal of Philosophical Studies, 9: 441-58.

Evans, G. (1982), The Varieties of Reference, McDowell, J. ed. Oxford: Oxford University Press.

Friedman, M. (1996), 'Exorcising the Philosophical Tradition: Comments on John McDowell's Mind and World', The Philosophical Review, 105: 427-67.

Gaskin, R. (2006), Experience and the World's Own Language. Oxford: Oxford University Press.

McDowell, J. (1982), 'Criteria, Defeasibility and Knowledge', Proceedings of the British Academy, 68: 455-79 Reprinted in McDowell 1998b: 369-94. (Page references here, and to McDowell 1986, 1992 and 1995 are to this reprint.)

- (1986), 'Singular Thought and the Extent of Inner Space', in P. Pettit and J. McDowell (eds), Subject, Thought, and Context. Oxford: Clarendon Press: 137-68. Reprinted in McDowell 1998b: 228-59.

_ (1992), 'Putnam on Mind and Meaning', Philosophical Topics, 20: 35-48. Reprinted in McDowell 1998b: 275-91.

— (1994), Mind and World. Cambridge, MA: Harvard University Press.

- (1995), 'Knowledge and the Internal', Philosophy and Phenomenological Research, 55: 877-93. Reprinted in McDowell 1998b: 395-413.

(1996), 'Introduction', in his Mind and World (With a New Introduction). Cambridge, MA: Harvard University Press: 11-24.

- (1998a), 'Responses to Commentators', Philosophy and Phenomenological Research, 68: 403-31.

(1998b), Meaning, Knowledge and Reality. Cambridge, MA: Harvard University Press.

(1999), 'Scheme-Content Dualism and Empiricism', in L. E. Hahn (ed.), The Philosophy of Donald Davidson. Chicago: Open Court: 87-104. Reprinted in McDowell 2009: 115-33. (Page references here, and to McDowell 2002, 2003 and 2006 are to this reprint.)

(2002), 'Gadamer and Davidson on Understanding and Relativism', in J. Malpas, U. Arnswald and J. Kertscher (eds), Gadamer's Century: Essays in Honor of Hans-Georg Gadamer. Cambridge, MA: MIT Press. Reprinted in McDowell 2009: 134-51.

- (2003), 'Subjective, Intersubjective, Objective', Philosophy and Phenomenological Research, 67: 675-81. Reprinted in McDowell 2009: 152-59.

- (2005), 'The True Modesty of an Identity Conception of Truth: A Note in Response to Pascal Engel (2001)', International Journal of Philosophical Studies, 13: 83-8. 
(2006), 'The Disjunctive Conception of Experience as Material for a Transcendental Argument', Teorema, 25: 19-33. Reprinted in McDowell 2009: 225-40.

(2007), 'Préface à l'Édition Française', in J. McDowell, L'esprit et le monde. Paris: Vrin: $7-9$.

- (2008a), 'Avoiding the Myth of the Given', in J. Lindgaard (ed.), John McDowell: Experience, Norm, and Nature. Blackwell: Oxford, 1-14.

_ (2008b), 'Responses', in J. Lindgaard (ed.) John McDowell: Experience, Norm, and Nature. Blackwell: Oxford: 200-67.

(2009), The Engaged Intellect: Philosophical Essays. Cambridge, MA: Harvard University Press.

Noë, A. (1999), 'Thought and Experience', American Philosophical Quarterly, 36: 257-65.

Peacocke, C. (2001), 'Does Perception Have a Nonconceptual Content?', Journal of Philosophy, 98: 239-64.

_ (2004), 'Explaining Perceptual Entitlement', in R. Schantz (ed.), The 'Challenge' of Externalism. Berlin: de Gruyter.

Pritchard, D. (2003), 'McDowell on Reasons, Externalism and Scepticism', European Journal of Philosophy, 11: 273-94.

- (2008), 'McDowellian Neo-Mooreanism', in A. Haddock and F. Macpherson (eds.)

New Essays on Disjunctivism. Oxford: Oxford University Press: 283-311.

Pryor, J. (2000), 'The Skeptic and the Dogmatist', Noûs, 34: 517-49.

Sellars, W. (1956), 'Empiricism and the Philosophy of Mind, Minnesota Studies in Philosophy of Science, vol. 1, Feigl, H. and Scriven, M. eds. Minneapolis: University of Minnesota Press. Reprinted in W. Sellars (1997) Empiricism and the Philosophy of Mind (With an Introduction by Richard Rorty and a Study Guide by Robert Brandom). Cambridge, MA: Harvard University Press.

_ (1968), Science and Metaphysics: Variations on Kantian Themes. New York: Humanities Press.

Wittgenstein, L. (1921), Tractatus Logico-Philosophicus, trans. D. F. Pears and B. F. McGuinness. London: Routledge \& Kegan Paul, 1961.

- (1953), Philosophical Investigations, trans. G. E. M. Anscombe. Oxford: Blackwell.

Wright, C. (2002), '(Anti-)Sceptics Simple and Subtle: G. E. Moore and John McDowell', Philosophy and Phenomenological Research, 65: 330-48.

- (2008), 'The Perils of Dogmatism', in S. Nuccetelli and G. Seay (eds), Themes from G. E. Moore: New Essays in Epistemology and Ethics. Oxford: Oxford University Press. 